\title{
Institutionalized adolescents in therapy: Narratives of psychotherapy and healing from sexual abuse
}

\author{
Gretchen Beiza $^{1 凶}$, Claudia Capella ${ }^{2}$, Denise Dussert ${ }^{3}$, Loreto Rodríguez ${ }^{3}$, Daniela Águila ${ }^{1}$, \\ Carolina Gutiérrez ${ }^{3}, \&$ Ximena Lama ${ }^{1}$
}

\begin{abstract}
Adolescent sexual abuse is a pressing social issue worldwide, specifically for institutionalized population that lack access to alternative care such as family-based options. This study examines narratives associated with healing from sexual abuse among teenagers in long-term residential care programs who have successfully completed specialized psychotherapy. Using a qualitative research methodology and multiple case analysis, in-depth interviews were conducted with five adolescents and then analyzed using thematic narrative analysis. Results show two different narrative positions regarding the meanings of healing after an experience of sexual abuse: narratives of healing and incomplete healing. In addition, factors that influence the healing process are observed, of which psychotherapy and therapeutic relationships are key. Study participants' own voices show the possibilities for generating recovery narratives among adolescents in residential care who have been sexually assaulted, highlighting aspects of therapeutic intervention that may better orientate psychotherapy for this specific group.
\end{abstract}

Keywords: healing, residential care, adolescent psychotherapy research

Sexual aggression in adolescence is a socially relevant and pressing topic, which has a complex response and multi-causal origin (United Nations Children's Fund [UNICEF], 2014). Diverse negative consequences on adolescents' psychological well-being are associated with sexual abuse, which despite having many influencing factors, affect different areas of development (Echeburúa \& Guerricaechevarría, 2005; Foster \& Hagedorn, 2014).

According to the worldwide report on violence against boys and girls (UNICEF, 2006), there may be as many as two million children and adolescents in residential care centers throughout the world. This report establishes parameters for diverse risk/protection factors, and institutionalization becomes an additional factor that makes an individual vulnerable to different types of violence, including

\footnotetext{
${ }^{1}$ Master in child and adolescent clinical psychology, Department of Psychology, University of Chile.

${ }^{2}$ Academic of Psychology Department, University of Chile.

${ }^{3}$ Psychologist, Department of Psychology, University of Chile.

$\square$ Corresponding author: Gretchen Beiza - Academic of Psychology Department, University of Chile; email to: gretchen.beiza@gmail.com
}

sexual violence.

In the present article, institutionalization is defined as a form of alternative care in long-term residences that offers full-time attention for adolescents who have been separated from their families. This occurs when an adolescent's psychosocial and physical integrity are at serious risk and no responsible caretaker is identified within the nuclear or extended family. It is recognized as an exceptional situation and should be temporary (Servicio Nacional de Menores [SENAME], 2014; UNICEF, 2003; Williamson \& Greenberg, 2010).

Life in residential centers results, in many cases, in the loss of parental (and other figures') involvement, which endangers or permanently interrupts their presence in the lives of the adolescent. This produces high levels of rootlessness between adolescents and their natural family and community environment (UNICEF, 2006).

A variety of international research studies have been carried out in order to better understand the consequences of institutionalization on adolescents (Brady \& Caraway, 2002; Delgado, Fornieles, Costas \& Brun-Gasca, 2012; Fernández \& Fuertes, 2005; Fisher, Gunnar, Dozier, Bruce \& Pears, 2006; Hul- 
burt, Leslie, Landsverk, Barth \& Slymen, 2004; Williamson \& Greenberg, 2010). Their results show the negative impact on adolescents' social and psychological levels, such as the presence of psychiatric symptoms, high rates of substance abuse, poor academic performance and retardation in physical growth.

It has also been observed that early institutionalization hinders emotional development. This is mainly attributed to the difficulties adolescents face in establishing close bonds with caretaker figures due to the high rotation of caregivers in these centers (Carcelén \& Martínez, 2008). This impact is also felt in their projections of the future; adolescents may find it difficult to establish long-term commitments in different areas of their lives due to an orientation towards the present (Carcelén \& Martínez, 2008).

Despite various studies on the effects of institutionalization, literature on psychotherapeutic interventions in residential centers is scarce. A Chilean study on specialized psychotherapy in this population is presented by Marchant (2014), who proposes a model of "therapeutic accompaniment". Here, repairing damage is seen not as symptomatic remission but as an approach to dealing with violence through caring and accompaniment. The therapeutic bond emerges as a repairing element, since it provides the child or adolescent with a different manner of relating to others - one that is not marred by violence or negligence (Marchant, 2014). This therapeutic approach is closely related to the aims proposed by specialized psychotherapy programs for adolescents who have been sexually assaulted, which encourage re-signification of sexual abuse by attributing new meanings to the experience (Barudy, 1998; Capella, 2011).

Taking into account the failure of previously revised studies to establish special guidelines for psychological treatment of sexual abuse among adolescents in residential care centers, this investigation expands on characteristics of the psychotherapeutic process. It contributes to a more accurate understanding and approximation to the phenomenon of overcoming sexual aggressions through adolescent narratives. Based on recent research on the topic of sexual aggressions (Capella, 2011; Draucker, Martsolf, Roller, Knapik, Ross \& Stidham, 2011), the concept of healing or overcoming in psychotherapy has been advanced in ways that understand that victims of abuse do not simply deal with negative consequences of an experience and then return to a prior level of functioning. Rather, by making a new sense of the experience, they see their personal resources strengthened and are able to generate a positive change in their lives. This process of growth and recuperation is seen as dynamic and complex, and it is built over time (Capella et al., in press; Draucker et al., 2011).

Draucker et al. (2011) propose a theoretical mod- el to describe healing from sexual abuse in adults, which includes four different stages of the healing process, five domains of functioning and six enabling factors that allow for movement from one stage to another. This model is based on several studies carried out with adults who had been sexually assaulted during their childhood and adolescence, regardless of their participation in psychotherapy. It is also represented by different stages that change over time; most people experience aspects affiliated with the first stage of the model, fewer participants identified with the following stages, and only a reduced number reached the final stages (Draucker et al., 2011). For this model, however, the healing process is marked by progress and setbacks. This implies that Child Sexual Abuse (CSA) survivors do not heal in an orderly and stepwise manner, as described by other authors (Banyard \& Williams, 2007).

Narratives related to different stages of healing vary from those described as incipient in this study, when an individual processes meanings of abuse and associated symptomatology, to narratives of healing as such, which show the possibility of overcoming negative effects of CSA and taking control of one's life course (Draucker et al., 2011). This investigation therefore explores meanings of overcoming and healing from experiences of sexual abuse through the narratives of adolescents that are currently enrolled in long-term residential care center, or were previously enrolled during the time of therapy, and who successfully completed psychotherapy in an external specialized program. It also sheds light on elements of the psychotherapeutic process that are considered to be fundamental in overcoming experiences of abuse.

The present study is part of a larger research project called "The process of healing from sexual aggressions: Narratives of the children and adolescents that have been victims, their parents and their psychotherapists". The main objective of this project is to characterize the process of healing from experiences of sexual aggression in children and adolescents by incorporating their perspectives as well as those of their parents and psychotherapists.

\section{Methodology}

A qualitative focus was employed when carrying out the present investigation. This study is exploratory-descriptive (Hernández et al., 2010) and is presented as a multiple case study, with the objective of providing helpful insight into complex social phenomena from the study of a limited number of cases (Kazez, 2009).

The participants of this study are five adolescents between the age of 13 and 17 who have successfully finished the therapeutic process in a specialized center for treatment of sexual abuse and maltreatment in Chile. These centers are funded by the $\mathrm{Na}$ - 
tional Service for Children and Adolescents in Chile (SENAME), which also provides guidelines for the different programs that work with adolescents in the country. Specialized treatment centers are separate from care residences and are distributed depending on location. They are staffed by a multidisciplinary team of professionals (Psychologists, Social Workers, Lawyers, among others) with specialized training in CSA. Therapy sessions are typically scheduled for once a week; they are carried out by psychologists while the rest of the team works with the adolescents' family or caregivers. Four of the study participants lived in residential care centers at the time that they were interviewed and throughout, or during the majority of, the psychotherapeutic process. The fifth adolescent, who had been enrolled in residential care during the psychotherapeutic process, was placed with a foster family once it was completed.

Most of the interviewees had more than one therapist present during their psychotherapeutic process. This is mainly due to the high rotation of professionals common to Chilean treatment centers and, in two cases, because of changes in the adolescents' residences. As SENAME guidelines state, all adolescents finish their psychotherapeutic process in the same specialized center even if their psychotherapist leaves the center; however, if the adolescent changes his/her residence, they must change centers and therefore start over again with a new therapist. Moreover, the four female adolescents who participated in the sample had female therapists during psychotherapy, while the only male in the sample had male therapists.

The duration of these interventions fluctuated between twelve and thirty-eight months, with an average of 25 months of therapy, and all adolescents completed therapy by meeting therapeutic goals. These goals are previously defined by therapists and adolescents, and according to SENAME guidelines for intervention in specialized centers, these respond to three major issues: putting a stop to the infringement of adolescents' rights, re-signifying experiences of sexual abuse and strengthening family and social resources (SENAME, 2014).

The main characteristics of the sample are presented in Table 1. Access to the sample was achieved in two ways: through direct contact with three specialized centers for the treatment of sexual abuse and maltreatment and through direct contact with the directors of two residential care centers. The process of inclusion of participants into the sample was carried out with the help of the therapists affiliated with each center or residency. The research strategy was developed by identifying cases, which resulted in successful completion of the psychotherapeutic process in a specialized center, and based on this condition, each case was revised to assure that it fulfilled the criteria to be included in the investigation (ethical, characteristics of inclusion, among others). Finally, the individuals included in the sample carried out their therapeutic process in 4 different specialized programs and live in 4 different residences.

The present study draws on in-depth interviews. Two interviews were carried out with each adolescent in Spanish and with guidelines elaborated by the research team, which addressed different thematic axes that supported greater comprehension of the recovery process from experiences of sexual aggression. Participants were asked to describe the following: their vision of change and overcoming difficulty; their vision of the psychotherapeutic process; aspects that facilitate overcoming an experience and aspects that hinder it; family support; the judicial process; their outlook on the future; bond with their biological family; presence of emotionally supportive figures within the residential care center; and finally, elements related to residential treatment that favor or hinder healing.

Interviews with adolescents were carried out by members of the research team. Authorization was requested through informed assent with the adolescents and through informed consent with their caretaker or the director of the residential care center. In addition, an interview was carried out with the therapists of the centers and/or psychologists at the centers in order to gather information about the characteristics of the participants and their therapeutic processes, as well as the elements that each professional considered necessary to include in the interview. Each interview was recorded and transcribed entirely for its subsequent analysis. Additionally, the research study was authorized by the Ethics Committee for the Investigation in Social Sciences and Humanities of the University of Chile, assuring the wellbeing of the participants, as well as the confidentiality of the information given, throughout the process.

Table 1. Sample characteristics

\begin{tabular}{lccccccc}
\hline Pseudonym & Gender & Age & $\begin{array}{c}\text { Type of Abu- } \\
\text { se }\end{array}$ & $\begin{array}{c}\text { Recurrence } \\
\text { of Abuse }\end{array}$ & Perpetrator of Abuse & $\begin{array}{c}\text { Duration of } \\
\text { Therapy }\end{array}$ & $\begin{array}{c}\text { Number of } \\
\text { therapists }\end{array}$ \\
\hline Josefina* & Female & 13 & Sexual Abuse & Repeated & $\begin{array}{c}\text { Acquaintance } \\
\text { Neighbor, Family Friend }\end{array}$ & 16 months & 1 \\
Jorge & Male & 15 & Sexual Abuse & Repeated & Mother's partner & 12 months & 3 \\
Mariela & Female & 17 & Sexual Abuse & Repeated & Father & 38 months & 3 \\
Fernanda & Female & 15 & Rape & Repeated & Neighbor & 28 months & 5 \\
Ágata & Female & 15 & Rape & Repeated & Father & 30 months & 3 \\
\hline
\end{tabular}

Note. ${ }^{*}$ These adolescent suffered two different sexual abuse experiences 
Narrative analysis was utilized when analyzing interviews. This technique is defined as the analysis of themes, structures and linguistic resources present within patient narratives in the context of a research study, and ultimately aims to better understand participant perspectives (Menard-Warwick, 2010). In the present study an individual analysis was first conducted for each interview in order to obtain thematic elements of the narratives (Riessman, 2008). In order to do so, the analysis of each interview was performed separately, followed by a reading of the complete text. This was intended to isolate the main narrative or meaning that each participant assigned to the themes proposed in the interview. Then, an integrated or inter-case analysis was carried out for each of the five interviews in order to identify common and dissimilar elements that arose from the participants' narratives, and then to finally generate a synthetic integration through schemes or an organizing matrix. Analysis and results were triangulated by other investigators on the research team, thus providing the investigation with greater methodological grounding.

\section{Results}

Based on the analysis of adolescents' narratives, the dimensions associated with healing from sexual assault are assigned different meanings. This fact allows us to establish two narrative positions in relation to the process of overcoming sexual assault experienced by adolescents. These are indicative of stages in the recovery process in which narratives of incipient healing constitute an initial stage that has not yet been completed but presents advancement, and narratives of healing as such, where adolescents perceive sexual aggression as something that can be overcome. It is important to emphasize that within the sample, the majority of narratives were of healing while the incipient narrative was observed in only one case.

The main characteristics of these narratives are presented here, organized according to three main themes and various thematic issues that emerged in the adolescents' narratives: meanings associated with the process of healing, meanings given to the therapeutic process and elements that influence the process of healing. Fragments of the adolescents' narratives are included while assuring anonymity through the use of pseudonyms for each participant's stories. Narrative positions that arise in the adolescents' narratives are indicated in each case.

\section{First Theme: Meanings Associated with the Healing Process}

The most relevant aspects of interviewees' narratives are related to the meanings individuals give to the process of healing from sexual abuse. Elements identified in their narratives are organized into five dimensions.
Change and strengthening. Within the adolescents' healing narratives (not in the incipient narrative), changes experienced during therapy are expressed in their perception of having matured, having developed an integrated emotionality and having strengthened personal resources like confidence and self-esteem. As Mariela states: “(...) so obviously with this problem I'd already gone through the bad part, and everything that happened from now on depended on me".

Possibility of talking about sexual aggression. A recurring theme among adolescents with narratives of healing is the possibility of talking about abuse as an important rupture in their lives. Individuals often perceive the psychotherapeutic process as a turning point where an experience of abuse can be overcome from that moment on. Ágata observed: "at first I didn't want to talk about anything that had happened to me (...). And then it was like for me, it was like talking about it like it was normal, what happened to me".

Meanwhile, for the adolescent with an incipient narrative, speaking about the aggression was largely negative, as in the case of Fernanda: "Interviewer: What do you feel when people talk to you about what happened?; Fernanda: "I get mad, I feel angry, I don't know".

Ways of thinking about sexual aggression. For adolescents with healing narratives, the experience of sexual aggression is not viewed as a central element in their lives, even though it is considered an important part of their story. It is possible to control the emergence of and negative emotions associated with that memory. Josefina observed: "When I think about it, I know it's important, but it's over (...). So you just have to look forward".

However, for narratives of incipient healing, the experience of abuse has negative connotations where negative feelings and associated memories are not susceptible to control. Fernanda indicates: (With regards to whether or not she will always remember the experience) "No. Only when someone reminds me and starts to talk about it. Ooooh! For me, it's very unpleasant".

Ongoing Process. In adolescents' healing narratives, the feeling of having overcome the experience is a process that does not end once therapy is complete. Instead, it is mainly associated with the perception that the abusive experience was an important part of their lives and that despite dealing with the memory, the experience continues to be present and will continue to exist, although with a reduced emotional effect. This allows adolescents to imagine a positive future, where overcoming is associated with personal growth in different domains of life. The following conversation of Ágata and her 
interviewer underscore this point:

"Interviewer: Do you feel that you were able to overcome the experience that led you to start therapy?; Agata: I would say more or less, because even if I'm asked about it now, it's still hard to talk about what happened to me. But it's not like at the beginning, when I would start crying and it was really hard to say".

Vision of the future. In narratives of healing, adolescents' outlook on the future corresponds to a moment in their lives in which goals and aspirations will be achieved, and where past experiences of sexual aggression are not a central point of focus. These narratives show the capacity that adolescents develop in dealing with the emotionality and arousal of painful memories associated with the traumatic experience, as well as an understanding of the experience as part of their lives which they are able to take control of again. As Mariela states: “(...) What comes now depends on me. I can't do anything with my past, but I can with my future".

On the other hand, for those narratives identified as incipient, visions of a positive future are conditioned by avoiding the topic of sexual aggression. Fernanda remarks: "I wish to be a beauty consultant (...); Interviewer: And regarding the memories of what happened to you?; Fernanda: To forget it, so that nobody talks to me about it, like goodbye, like it didn't happen to me".

\section{Second Theme: Meanings Given to the Thera- peutic Process}

This section presents narratives that expose elements associated with psychotherapy, which are considered relevant in overcoming the experience of sexual abuse. Several dimensions are identified.

\section{Psychotherapy seen as a process with different} stages. In narratives of healing, the adolescents interviewed indicate that psychotherapy is a process characterized by different moments. Three main phases are identified: entry into therapy, development and closure of the therapeutic process. Each phase seems to have it's own particularities. Nonetheless, psychotherapy is seen as a process of acquiring tools, visualizing personal resources and overcoming the traumatic experience. As Mariela remarks: "Before (...) I was behind a wall, and saw everything from behind it, and now I decided to go through it".

Adolescents also point out that building trusting relationships with their therapist is a turning point in both the psychotherapeutic and healing process. This moment gives way to a second, when the adolescents are able to give a new meaning to therapy and gradually tackle the experience of sexual aggression, ushering in the therapeutic process per se. Jorge observed: (regarding the moment he began to feel better)
"When I trusted Alfredo (his therapist). Yeah, when I came here we would talk, and I, like, felt good".

From the narrative identified as incipient in this axis, the closure of the therapeutic process was experienced as something abrupt, in which elements were left inconclusive. It implies that if the process had continued, the adolescents would have changed the course of their therapy. It is important to mention that in the case of the following adolescent, there were many changes between therapists and specialized centers in charge of the intervention. As a result, the continuity of treatment was impacted and the individual's possibilities for overcoming the experience of aggression were negatively affected. The following conversation reflects Fernanda's position:

"It was, like, really sudden the change (...). The months and days passed by really fast. And then the therapy was over; Interviewer: Would you have preferred it to continue? Would it have been different?; Fernanda: Yes, I think so".

Psychotherapy as a space where sexual aggression is talked about as well as other topics. Throughout their narratives of healing, adolescents visualized the therapeutic space as one that allows the emergence of different topics, including but not limited to sexual abuse. Indeed, throughout therapy other topics start to gain a new importance. As Jorge pointed out: "I have gone through a lot of psychologists (..) and this was, like, more serious, it was like talking about it, he would ask me how I am, and not so much what happened".

Meanwhile, for narratives identified as incipient, therapy was considered the same as previous interventions where topics related to the experience of aggression were covered without the appearance of change or positive elements. As Fernanda commented: "No, all the therapies I've been to, it has never been different for me (...) They ask the same thing. They look at the same topic. Aaaaah! It is so boring!”.

Psychotherapy as a space of learning and change. For narratives of healing, therapy is seen as a space that allows an individual to learn about oneself, embrace personal resources and generate changes from newly acquired knowledge. In this sense, it becomes a space of learning and strengthening capacity in which personal effort and support by professionals of the specialized centers are key to promoting personal change. Psychotherapy supports the notion of progress in adolescents' development. As Josefina remarks: "I did, like, fifty percent and they did fifty percent (...) each interview that, each session, I would take something good away, and, like, some kind of lesson and I would reinforce it and reinforce it".

Within these narratives are lessons related to resignifying the loss of significant figures. This is directly tied to the dynamics of residential care cen- 
ters, in which the frequent rotation of personnel gives way to a breakdown in the relationship with people who provide care and protection. A reflection on this topic emerges in Mariela's narrative (with regards to the high rotation of direct-contact educators in her institution):

"To be honest, at the beginning I felt bad, because every time I started to care about someone, they would leave. But, one time an 'aunty' passed through here and she told me that I shouldn't feel bad or angry because people leave. I have to, like, treasure the good memories and the lessons they taught me. So, before it burt me, but not now".

Within narratives identified as incipient, therapy was observed to be a space promoting behavioral change rather than strengthening personal resources. As Fernanda indicates: "If I feel bad, I'm not going to treat another person badly, it's not their fault; Interviewer: And that is a something you learned here? Yes, it is".

Psychotherapy as a space of distraction and wellbeing. One element that stands out in narratives identified as "healing narratives" is the visualization of therapy as a ludic space which serves as a distraction for adolescents. This may be due to the fact that it takes place outside of the residential center, or because it is another type of activity then what they are used to. Moreover, the adolescent is introduced to other life experiences that facilitate a sense of well-being, although this ultimately depends on the space as well as the therapist. Josefina observed (with regards to what advice she would give to other adolescents starting therapy): "they should see that you don't only come here to talk to a psychologist (...) Like, we would sometimes tell jokes, we would play".

The importance of the therapeutic figure. The importance of the therapist is an emerging theme in all healing narratives, and it appears to be a decisive element in overcoming an experience of abuse. While healing is conditioned by different factors, it is clear that adolescents signify the therapist as someone of great relevance in the healing process and something that promotes change in their lives. As Jorge stated: "I think that if I didn't have him (the therapist) it would've" been difficult to go ahead, or, I don't know, to express my feelings".

Within the incipient narratives, adolescents' resistance to establishing trusting bonds with their therapist stands out, which is driven by the constant change of therapists during the process and is thus perceived as a hindering factor. Fernanda pointed out (With regards to what advice she would give to other adolescents starting therapy) : "That they let themselves be helped (..). There are people that want to help you, but if you don't know how to take advantage (of that help) you push them away".

\section{Third Theme: Elements that Influence the Healing Process}

Within the axis presented, elements in adolescents' narratives that play a fundamental role in the process of overcoming sexual abuse - either by enabling or hindering the healing process - are described.

Personal Characteristics. Adolescents' narratives of healing draw attention to personal characteristics, such as strength, perseverance and self-esteem, as essential elements that allowed them to address and overcome experiences of sexual aggression. Ágata remarks: "I would say strength, because since I was little I didn't always have the love of my parents or whatever. It's like, I learned to be strong with time".

Significant Figures. All of the adolescents' narratives identify vital figures in overcoming experiences of abuse and creating personal change, whether they facilitate or hinder the process. With regards to the role of their biological or family of origin, both narrative positions are negative. This is mainly because of the lack of credibility given to the adolescents when revealing the experience of sexual aggression, the absence of attention, care and love, as well as the phenomenon of family 'rootlessness' that comes about after entering a residential care facility. As Ágata points out: "I always thought about how my mom could be here now, next to me, supporting me, but she wasn't".

Regarding figures in the residential center, for both narrative positions the degree of bonding that adolescents develop with these individuals influences their notion of support in the process of overcoming abuse. Josefina states: "I also talked to a psychologist from the residence, so I trust her a lot as well, so we would talk, so she helped me a lot to get over this".

Lastly, in relation to the role that other significant figures play, such as partners or friends, the possibility of overcoming the experience of sexual aggression is strengthened when these figures are involved. In addition, there is a possibility of relating to them in contexts that are free of the traumatic experience, like Fernanda: "Interviewer: What helped you to feel better during the process?; Fernanda: I think it was entering the cueca (Chilean dance) club and meeting my boyfriend".

Residential Care. With regards to the role the residential care center plays in the narratives of adolescents, there are multiple points of view. On the one hand, the residential space becomes an important factor in the process of overcoming abuse. As Josefina pointed out: "I think that being in the residence made the process of overcoming a lot easier, because if I had been at my house, I don't think I would have come every time they called me". However, in some cases adolescents are ambivalent, like Ágata: "Uuum, I would say, like, it's not diffi- 
cult or favorable (...) for me, what affected me the most was not being with my family".

On the other hand, it is possible to observe that from the incipient narrative, the protective residential space is a negative setting which does not favor overcoming and represents a break in their life continuum. Fernanda states: "I look at where I live and it's a downer. Because you don't live like a normal girl. If someone tried to deny that, it would be a mistake".

Judicial Process. Both narrative positions reveal a variety of elements and positions with regards to the judicial process. Judicial actions or events are viewed favorably when they provide protection and interrupt situations of abuse. This reinforces the credibility of the system in providing support to affected adolescents. Mariela remarks: "Uum I think that it was more than a help because they separated me from my dad (aggressor) and when I was with my dad, he did that stuff, so I think it was for the better".

Meanwhile, legal aspects of the judicial process are negatively perceived by all participants. Lack of conviction of the aggressor, as well as experiences of secondary victimization during the process, when the judicial system is seen as being abusive to victims, are perceived as unjust. In this sense, the judicial system emerges as an obstacle to the process of overcoming. As Âgata pointed out: "Ohh I hated it. They ask me like 10 times the same things, like telling everybody, so I told it one time and no more".

Reiterated Psychological Processes. In both narrative positions adolescents reiterate psychological processes, some of which are experienced without closure or adequate transfer (from one professional to another). This is an element that causes resistance when initiating a new therapeutic process and hinders the possibility of overcoming experiences of sexual abuse. As Ágata notes: "I told the Social Worker that I didn't want to go anymore because I had to tell her the same thing that happened to me and I was bored already of explaining the same thing".

\section{Conclusions}

The findings that emerge from this investigation reveal two different narrative positions. Primary stages of the healing process - called narratives of incipient healing - are marked by difficulties in resignifying a traumatic experience and integrating it into the life cycle, and are associated with the negative consequences of the experience. Those narratives, observed mostly in Fernanda's case, substantiate prior research findings related to the initial stages of the healing process (Draucker et al., 2011). In this particular case, although the adolescent's therapist confirms that she achieved therapeutic goals - as with the rest of the cases - her narrative does not necessarily corroborate this decision.
Therefore, overcoming the traumatic experience is not considered to be a finished process.

A second position, called narratives of healing, establishes the possibility of giving new meaning to the experience of abuse and integrating it into one's life story through a dynamic process of change. This involves strengthening personal resources and looking forward to a future where experiences of sexual abuse are an important, but not central part of one's history. These narratives are representative of a complete process of healing. This is also observed by previous research with adolescents in Chile (Capella, 2011; Capella et al., in press; Lama 2014) and international studies carried out with adults (Draucker et al., 2011; Saha, 2011).

Identifying these positions allows us to focus our attention on those elements that, from the perception of the adolescents themselves, are considered relevant when moving from a narrative of incipient healing to one of healing as such. This contributes to the practical implications of therapeutic work with adolescents that have been victims of sexual abuse.

For adolescents whose narratives indicate healing from abuse, psychotherapy is seen as a process that occurs in different phases or moments, which are essential to overcoming the experience. The first phase corresponds to the beginning of the therapeutic process. Adolescents understand this as a complex phase, mostly due to the difficulties associated with talking about the topic of abuse. It is also marked by the creation of a therapeutic bond or alliance, which is seen as a turning point in the process of healing - described in the literature as critical life events, both positive or negative, which lead to changes in one's lifespan. This allows an individual to transcend the experience of sexual abuse rather than cope with it (Banyard \& Williams, 2007; Draucker et al., 2011). The possibility of establishing a bond with another figure in the therapeutic context favors the re-signification of traumatic experiences (Horvarth \& Bedi, 2002) as well as the reestablishment of trust in others, which is often difficult for survivors of sexual abuse (Finkelhor \& Browne, 1985). This has favorable repercussions with regards to individuals' perception of healing (Nelson-Gardell, 2001). In addition, this was observed by Lama (2014) with adolescent victims of sexual abuse who live with their families. The findings allow us to hypothesize that for adolescents in residential care programs, therapeutic relationships are especially relevant because they do not have a bond with their families.

The possibility of talking about sexual aggression in therapy is also signified as a turning point in the healing process. In this sense, tackling a traumatic experience in a setting that guarantees protection and trust appears to promote wellbeing and support the process of overcoming, despite it being difficult and painful. This process is seen as necessary in ad- 
vancing in therapy, and it marks the start of a second phase in the therapeutic process and overcoming the traumatic event at the same time. Moreover, according to the adolescents themselves, the framework of trust that the therapeutic bond provides is key. The therapist is seen as a figure that respects the personal timing of each patient, including other topics not related to the sexual aggression, with the objective of facilitating adolescents' experiences of handling the abusive experience.

Finally, the last phase is related to the closure of the therapeutic process; while it has different characteristics for each adolescent, it is signified as an important milestone. It is possible to understand lessons learned and reflect on the traumatic experience without reliving the emotional impact it initially caused. This in turn allows adolescents to imagine future possibilities where aggression does not become an axis of their personal narrative, even though it is not forgotten.

These therapeutic phases are similar to those identified within the larger sample of the research study (Capella et al., in press). However, in contrast with the results of the main study (Capella et al., in press), family figures do not have a key role in the healing processes in the narratives of the adolescents in this sample. This is closely related to their involvement in residential care centers and consequential family rootlessness (UNICEF, 2006). In this sense, tackling themes or topics associated with the stage of life the adolescents are in, as well as elaborating the meanings associated with experiences of abandonment or neglect by their family of origin, constitute central elements in therapeutic intervention. This allows adolescents to heal from the experience of sexual aggression, as well as integrate other painful life stories into their personal narrative.

For this particular sample, the complexities associated with family 'rootlessness' stand out in terms of the disruptions that are produced with significant figures, which limits the establishment of emotional bonds that help to re-signify experiences of sexual aggression. The need for stable figures within the residential centers and in the therapeutic process becomes relevant, and they are considered emotional models for institutionalized adolescents. It is also important to strengthen bonds with extended family who give credibility to the adolescent during the therapeutic intervention. This has also been pointed out by Carcelén and Martínez (2008) and Marchant (2014).

It is observed that inability to establish a close bond with a caretaker, as well as the loss of family bonds, greatly impacts the lives of adolescents in residential care centers. It is an important topic within the therapeutic process, and is key to assigning new meanings to life stories of maltreatment and neglect. Therefore, re-signification of both sexual abuse experiences and repairing the loss of significant family bonds should be the central axis of a therapeutic process which seeks to complete the healing process.

Another important element in this sample is the role of residential care centers and the people who work on the healing and therapeutic process of adolescents. There is no single viewpoint, however, and adolescents vary on how they perceive the role of residential care centers. Some believe it can favor or hinder the therapeutic process, depending on the bonds the adolescents have established.

Participants' own voices show us the possibility of generating narratives of healing among institutionalized adolescents who have been sexually assaulted, as well as the importance of psychotherapy and emotional bonds with significant figures (therapist, professionals, and others) during this process. On the other hand, challenges associated with the psychotherapeutic process are identified, which involve not only overcoming the experience of sexual aggression, but at the same time, redeeming the work of giving new meanings to experiences of loss and growing apart from significant family figures.

On the one hand, the present study advances our understanding of this phenomenon from the voice of individuals who are involved, thereby building on national and international studies which explore adolescents' perception of re-signifying and healing (Capella, 2011; Capella et al., in press; Foster \& Hagedorn, 2014; Lama, 2014; Nelson-Gardell, 2001). It also fills a gap in research on the therapeutic experiences of adolescents in residential care programs (Leve, Harold, Chamberlain, Landsverk, Fisher \& Vostanis, 2012).

On the other hand, this study contributes to characterizations of overcoming experiences of abuse according to institutionalized adolescents using their own narratives. It emphasizes the meanings that adolescents assign to their own process, as well as their views of the therapeutic experience. This allows us to identify distinctive elements for this particular population, which may guide clinical work.

The need for a therapeutic space that promotes the incorporation of new meanings of an abusive experience becomes possible through strengthening personal resources and building new competencies, all without centering the intervention solely on the remission of symptomatology or on the negative consequences of the sexual aggression (Capella et al., in press). With regards to the practical implications of therapeutic work, the findings of this study indicate that the healing process transcends the moment of psychotherapy. Instead it becomes a process that allows patients to make sense of the traumatic experience in a continuous manner throughout their lifetime, with differential characteristics that correspond to particular stages of evolutionary development. This was also observed in the results of the larger research study (Capella et al., in press).

It is also important to resolve the antagonism felt 
by adolescents towards the judicial system, which they view in a positive light because it provides safety, but also negatively because it draws them into the criminal justice system. This finding highlights the important role the justice system plays in the lives adolescents in residential care centers, since it affords them security and protection by interrupting the abusive situation - an element that does not appear in non-institutionalized adolescents from the larger research sample (Capella et al., in press; Lama, 2014).

Study limitations include reduced sample size and limited variability (in terms of gender, type of abuse, among others), which makes it difficult to generalize results. Moreover, only cases marked by the successful completion of the therapeutic process were included, which excludes the narratives of adolescents who did not participate in psychotherapy and still overcame sexual abuse, as well as those who have not successfully finished the process. This would have allowed us to observe different factors that favor or hinder healing from a sexual abuse experience. Additionally, this study was focused on adolescents' narratives regarding their therapeutic process, despite the availability of research methods in this area that emphasize nonverbal and observation techniques (Alaggia, 2004). Moving forward, it would be interesting to comparatively study the narratives of healing from sexual abuse developed by adolescents that are affiliated with and unaffiliated with residential care centers.

Lastly, this research brings visibility to the voices of institutionalized adolescents in terms of their needs in a therapeutic setting, the elements that adolescents feel are relevant when opening up about their inner worlds and their experiences with significant caretaker figures, and it validates their personal narratives. To listen to these voices requires a substantial commitment on behalf those working with adolescents who bravely and with much personal effort walk a path marked by pain towards a promising future, full of hope.

\section{Acknowledgments}

Authors' note: We are thankful for the support and funding provided by the Academic Productivity Support Program PROA VID 2015 University of Chile and this research is part of Proyect U-INICIA 5/0612 Program U-INICIA VID 2012, University of Chile.

\section{Notes}

1. This is the way children and adolescent in residential care centers in Chile refer to caretakers and professionals.

\section{References}

Alaggia, R. (2004). Many ways of telling: expanding conceptualizations of child sexual abuse disclosure. Child Abuse \& Neglect, 28 (11),1213-1227.
Banyard, V. \& Williams, L. (2007). Women's voices on recovery: A multi-method study of the complexity of recovery from child sexual abuse. Child Abuse \& Neglect, $31,275-290$.

Barudy, J. (1998). El dolor invisible en la infancia: Una lectura ecosistémica del maltrato infantil [The invisible pain in childhood: An ecosystemic reading of child maltreatment]. Barcelona: Paidos Ibérica.

Brady, K. \& Caraway, L. (2002). Home away from home: Factors associated with current functioning in children living in a residential treatment setting. Child Abuse \& Neglect, 26, 1149-1163.

Capella, C. (2011). Hacia narrativas de superación: El desafio para la psicoterapia con adolescentes de integrar la experiencia de agresión sexual a la identidad personal [Towards narratives of healing: The challenge for adolescents' psychotherapy to integrate the experience of sexual assault to personal identity] (doctoral thesis). Universidad de Chile, Santiago, Chile.

Capella, C. (2013). Una propuesta para el estudio de la identidad con aportes del análisis narrativo [A proposal for the study of identity with contributions of narrative analysis]. Psicoperspectivas, 13(2), 117-128.

Capella, C., Lama, X., Rodríguez, L., Águila, D., Beiza, G., Dussert, D. \& Gutiérrez, C. (in press). Winning a Race: Narratives of Healing and Psychotherapy in Children and Adolescents Who Have Been Sexually Abused. Journal of Child Sexual Abuse.

Carcelén, M., \& Martínez, P. (2008). Perspectiva temporal futura en adolescentes institucionalizados [Future time perspective in institutionalized adolescents]. Revista de Psicología Universidad Católica del Perú, 16(2), 255-276.

Delgado, L., Fornieles, A., Costas, C., \& Brun-Gasca, C. (2012). Acogimiento residencial: Problemas emocionales y conductuales [Residential care: emotional and behavioral problems]. Revista de Investigación en Educación, 10(1), 158-171.

Draucker, C., Martsolf, D., Roller, C., Knapik, G., Ross, R., \& Stidham, A. (2011). Healing from Childhood Sexual Abuse: A Theoretical Model. Journal of Child Sexual Abuse, 20(4), 435-466.

Echeburúa, E. \& Corral, P. (2005). ¿Cómo evaluar las lesiones psíquicas y las secuelas emocionales en las víctimas de delitos violentos? [How to evaluate psychic damage and emotional sequelae in victims of violent crimes?]. Psicopatología Clínica, Legal y Forense, 5, 57-73.

Fernández, J. \& Fuertes, J. (2005). El acogimiento residencial en la protección a la infancia [The Residential care in child protection]. España: Pirámide.

Finkelhor, D., \& Browne, A. (1985). The traumatic impact of child sexual abuse: A conceptualization. American Journal of Orthopsychiatry, 55(4), 530-541.

Fisher, P., Gunnar, M., Dozier, M., Bruce, J., \& Pears, K. (2006). Effects of a therapeutic intervention for foster children on behavior problems, caregiver attachment, and stress regulatory neural systems. Annals of the New York Academy of Sciences, 1094, 215-225.

Foster, J., \& Hagedorn, B. (2014). Through the Eyes of the Wounded: A Narrative Analysis of Children's Sexual Abuse Experiences and Recovery Process. Journal of Child Sexual Abuse, 23 (5), 538-557.

Hernández, R., Fernández, C. \& Baptista, P. (2010). Metodología de la investigación. [Investigation Methodology] México: Editorial Mc Graw-Hill.

Horvath, A.O., \& Bedi, R.P. (2002). The Alliance. In Norcross, J. (Ed.) Psychotherapy Relationships That Work ( $p p$. 37-69). New York: Oxford University.

Hulburt, M., Leslie, L., Landsverk, J., Barth, R., \& Slymen, D. (2004). Outpatient mental health services for children in foster care: A national perspective. Child Abuse \& 
Neglect, 28(6), 697-712.

Kazez, R. (2009). Los estudios de casos y el problema de la selección de la muestra: Aportes del sistema de matrices de datos. [Case Study and the sample choosing problem: Contributions from matrices data system]. Subjetividad $y$ procesos cognitivos, 13(1), 71-89.

Lama, X. (2014). Narrativas de superación de adolescentes que han sido víctimas de agresiones sexuales $y$ de sus terapeutas [Healing narratives of adolescents that have been victims of sexual abuse and their therapists]. (Master dissertation). Universidad de Chile. Santiago, Chile.

Leve, L., Harold, G., Chamberlain, P., Landsverk, J., Fisher, P., $\&$ Vostanis, P. (2012). Practitioner review: Children in foster care vulnerabilities and evidence-based interventions that promote resilience processes. Journal of Child Psychology and Psychiatry, 53(12), 1197-1211.

Marchant, M. (2014). Vinculo y memoria. Acompañamiento terapéutico con niños internados [Bond and Memory. Therapeutic accompaniment with institutionalized children]. Santiago, Chile: Editorial Cuarto Propio.

Nelson-Gardell, D. (2001). The Voices of victims: Surviving child sexual abuse. Child and Adolescent Social Work Journal, 18(6), 401-416.

Riessman, C. (2008). Narrative methods for the human sciences. California: Sage Publications.
Saha, S., Cheung, M. \& Thorne, L. (2011). A narrative exploration of the sense of self of women recovering from childhood sexual abuse. Counselling Psychology Quaterly, 24 (2), 101-113.

Servicio Nacional de Menores (SENAME) (2014). Catastro de la Oferta Programática de la red SENAME [Programmatic offering of SENAME network]. Retrieved from http://www.sename.cl/wsename/otros/op/ CATASTRO-201405.pdf

United Nations Children's Fund [UNICEF] (2003). Children in institutions: The beginning of the end? The cases of Italy, Spain, Argentina, Chile and Uruguay. New York: UNICEF.

United Nations Children's Fund [UNICEF] (2006). World Report on Violence Against Children. New York: UNICEF.

United Nations Children's Fund [UNICEF] (2014). Hidden in Plain Sight: A statistical analysis of violence against children. UNICEF, New York.

Williamson, J., \& Greenberg, A. (2010). Families, Not Orphanages. New York: Better Care Network.

Submitted: July 2015

Accepted: October 2015

Published: December 2015 